\title{
Osmium density challenge
}

\section{John W. Arblaster}

(C) Springer-Verlag Berlin Heidelberg 2014

We would like to invite you to participate in the Analytical Challenge, a series of puzzles to entertain and challenge our readers. This special feature of "Analytical and Bioanalytical Chemistry" has established itself as a truly unique quiz series, with a new scientific puzzle published every other month. Readers can access the complete collection of published problems with their solutions on the ABC homepage at http://www.springer.com/abc. Test your knowledge and tease your wits in diverse topics of analytical and bioanalytical chemistry by viewing this collection.

In the present challenge, "density" is the topic. And please note that there is a prize to be won (a Springer book of your choice up to a value of $€ 100)$. Please read on...

\section{Meet the challenge}

Although metals can now be obtained with a high degree of purity, it is still difficult to produce defectfree materials. The density of "perfect" crystals is therefore calculated from a combination of atomic weights, lattice parameters, and the Avogadro Constant. This method makes use of crystallography to determine the density of the crystal unit cell, i.e., the ratio of the unitcell mass and volume. The atomic mass of the crystal unit cell can be readily obtained from the atomic weights of the constituent elements. The atomic volume of the crystal unit cell, on the other hand, is estimated from X-ray diffraction measurements.

J. W. Arblaster $(\square)$

Wombourne, West Midlands, UK

e-mail: jwarblaster@yahoo.co.uk
Consider copper, which has a face-centred cubic crystal structure, similar to caesium iodide. A unit cell contains four copper atoms: eight one-eighths of an atom at the edges of the unit cell, and six half-atoms at the faces of the unit cell. Thus, the molar mass of the unit cell is $4 \times M(\mathrm{Cu})=4 \times 63.546(3)$ $\mathrm{g} / \mathrm{mol}^{-1}$. The lattice parameter $a=0.36150(3) \mathrm{nm}$, and the volume $V=a^{3}=47.242(12) \times 10^{-30} \mathrm{~m}^{3}$. Consequently, the density of copper can be obtained as follows:

$$
\begin{aligned}
\rho= & 4 M(\mathrm{Cu}) /\left(N_{\mathrm{A}} V_{\mathrm{a}}\right)=4\left(63.546(3) \mathrm{g} \mathrm{mol}^{-1}\right) / \\
& \left(6.02214129(27) \times 10^{23} \mathrm{~mol}^{-1} \times 47.242(12) \times 10^{-30} \mathrm{~m}^{3}\right) \\
= & 8935(2) \mathrm{kgm}^{-3}
\end{aligned}
$$

What is the densest metal? The answer to this seemingly simple question has been the subject of much confusion, mostly because of the problems in obtaining accurate atomic weights for the two candidate metals: osmium and iridium.

In 1933 Owen and Yates determined the lattice parameter of iridium and calculated a density of $22.65 \mathrm{~g} \mathrm{~cm}^{-3}$ on the basis of the then-accepted atomic weight of 193.1, and in 1935 Owen et al. determined the lattice parameters of osmium and calculated a density of $22.61 \mathrm{~g} \mathrm{~cm}^{-3}$ on the basis of an atomic weight of 190.8 , even though the atomic weight had been revised in 1934 to what proved to be an inaccurate value of 191.5. The density values of $22.65 \mathrm{~g} \mathrm{~cm}^{-3}$ for iridium and $22.61 \mathrm{~g} \mathrm{~cm}^{-3}$ for osmium continued to be quoted until 1955 , suggesting that iridium was the densest metal (Table 1).

In 1955 Swanson et al. re-determined the lattice parameters for both metals and calculated a density of $22.661 \mathrm{~g} \mathrm{~cm}^{-3}$ for iridium. This value was calculated on the basis of the obsolete atomic-weight value of 193.1, despite the fact that the accepted atomic weight of iridium had been reduced to 192.2 in 1953. Meanwhile, a density of $22.583 \mathrm{~g} \mathrm{~cm}^{-3}$ was given for osmium on the basis of the latest atomic weight of 190.2. Yet again, iridium was believed denser than osmium, although a 
Table 1 Current data pertinent to calculating the density of iridium and osmium ${ }^{\mathrm{a}}$

Osmium
Standard atomic weight
Crystal structure
Number of atoms in a unit cell

${ }^{\mathrm{a}}$ The currently accepted value for the Avogadro Constant is $N_{\mathrm{A}}=6.02214129(27) \times 10^{23} \mathrm{~mol}^{-1}$ [5]

proper choice of $A_{\mathrm{r}}(\mathrm{Ir})$ would have yielded $22.555 \mathrm{~g} \mathrm{~cm}^{-3}$ for iridium, thus making osmium the densest metal. This episode in the history of crystallography indicates the importance of atomic weights.

\section{The challenge}

The question of which metal is denser, osmium or iridium (at room temperature, at least), was not solved until the 1979 review by Crabtree, who calculated densities of $22.59 \pm$ $0.02 \mathrm{~g} \mathrm{~cm}^{-3}$ for osmium and $22.57 \pm 0.01 \mathrm{~g} \mathrm{~cm}^{-3}$ for iridium. Although these results suggested that osmium could be the densest metal, they overlapped somewhat and no confident conclusion could be made at the time.

In 1995 the atomic weight of iridium was revised to $192.217 \pm 0.003$, which altered neither the density value nor its accuracy, and the atomic weight of osmium was now calculated to be $190.23 \pm 0.03$, leading to a density of 22.587 $\pm 0.009 \mathrm{~g} \mathrm{~cm}^{-3}$. The difference of $0.025 \pm 0.013 \mathrm{~g} \mathrm{~cm}^{-3}$ was now regarded as significant enough to suggest that osmium was the densest metal at room temperature [1]. Further refinements of the selected lattice parameter values by this author, for iridium in 2010 [2] and osmium in 2013 [3], led to density values of $22.562 \pm 0.011 \mathrm{~g} \mathrm{~cm}^{-3}$ and $22.589 \pm 0.005 \mathrm{~g} \mathrm{~cm}^{-3}$, respectively, with the difference of $0.027 \pm 0.012 \mathrm{~g} \mathrm{~cm}^{-3}$ further supporting the higher value for osmium.

However, it is uncertain whether this conclusion will remain constant. The atomic weight of iridium has now been determined with great precision and is unlikely to change by more than a small amount. However, the currently accepted atomic weight of osmium is based on only one set of experiments, and its value is therefore likely to be revised in the near future by the Commission on Isotopic Abundances and Atomic Weights.

What would the atomic weight of osmium have to change to in order for iridium to become the densest metal?

\section{References}

1. Arblaster JW (1995) Platin Met Rev 39:164

2. Arblaster JW (2010) Platin Met Rev 54:93-102

3. Arblaster JW (2013) Platin Met Rev 57:177-185

4. Wieser ME et al (2013) Pure Appl Chem 85:1047-1078

5. Mohr PJ et al (2012) Rev Mod Phys 84:1527-1605

We invite our readers to participate in the Analytical Challenge by solving the puzzle above. Please send the correct solution to abc-challenge@springer.com by August 1, 2014. Make sure you enter "Osmium density challenge" in the subject line of your e-mail. The winner will be notified by email and his/her name will be published on the "Analytical and Bioanalytical Chemistry" website at http://www.springer. com/abc and in the journal (volume 406/issue 27) where the readers will find the solution and a short explanation.

The next Analytical Challenge will be published in 406/22, September 2014. If you have enjoyed solving this Analytical Challenge you are invited to try the previous puzzles on the $A B C$ homepage. 